\title{
Assessing the chemical involvement of limestone powder in sodium carbonate activated slag
}

\author{
B. Yuan · Q. L. Yu • H. J. H. Brouwers
}

Received: 1 November 2016/Accepted: 24 January 2017/Published online: 9 February 2017

(C) The Author(s) 2017. This article is published with open access at Springerlink.com

\begin{abstract}
This study aims to investigate the effect of limestone powder (LP) on the reaction of sodium carbonate activated slag. The results show that the incorporated LP up to $30 \%$ improves the strength development, especially at advanced curing ages. A slightly accelerated reaction is observed for samples containing low amount of LP $(\leq 5 \%)$, while mixture with $10 \%$ LP shows the optimized results with respect to the heat release and strength development. Chemical effect of incorporating LP is observed at high replacement levels $(\geq 15 \%)$, indicated by the formation of a new phase, natron $\left(\mathrm{Na}_{2} \mathrm{CO}_{3} \cdot 10 \mathrm{H}_{2} \mathrm{O}\right)$. Besides, relatively high contents of hydrotalcite-like phases are generated when increasing the dosage of limestone powder. The chemical changes, including the volume changes of generating natron and the transformation of natron to calcite, is potentially responsible for the enhanced mechanical properties.
\end{abstract}

B. Yuan · Q. L. Yu ( () ) H. J. H. Brouwers

Department of the Built Environment, Eindhoven

University of Technology, P.O. Box 513,

5600 MB Eindhoven, The Netherlands

e-mail: q.yu@bwk.tue.nl

B. Yuan · H. J. H. Brouwers

State Key Laboratory of Silicate Materials for

Architectures, Wuhan University of Technology,

Wuhan 430070, People's Republic of China
Keywords Limestone powder - Sodium carbonate activated slag · Chemical effect · Reaction kinetics · Reaction products $\cdot$ Mechanical properties

\section{Introduction}

Alkali activated materials (AAM) have been attracting worldwide attention during the last few decades because of their good material properties and environmental benefits [1]. Nevertheless, depending on the used raw materials and alkaline solutions, the performance of the resulted materials can be varied $[2,3]$. At present, most attentions are paid to the development of mixtures with higher strength, or improved durability, upgrading the-state-of-the-art of AAM [4-7]. However, the effects of supplementary materials on the reaction of AAM are rarely studied, especially their potential chemical involvement.

As a supplementary material, limestone powder (LP) has been widely applied in Portland cement based building materials because of its low price and good performance [8-12]. The effect of LP on the hydration of cement has been intensively investigated, ranging from the filler effect to the chemical involvement in cement hydration: (1) inert filler acting as nuclei sites; (2) accelerating the hydration of $\mathrm{C}_{3} \mathrm{~S}[13,14]$ and (3) reacting with $\mathrm{C}_{3} \mathrm{~A}$ forming calcium carboaluminates [14-16]. However, the function of LP on the reaction of alkali activated materials has not been 
systematically studied yet. Up till now, only limited efforts [17-19] have been devoted to this topic partly because the system of alkali activated material (AAM) is more complex than Portland cement system due to the different activators and raw materials applied $[1,20,21]$.

It is reported that in the low-calcium containing alkali activated metakaolin system, LP is dissolved in the sodium hydroxide solution and its presence enhances the release of $\mathrm{Al}$ and $\mathrm{Si}$ ions from metakaolin, leading to the formation of layered calcium carboaluminates [17]. While in high-calcium containing alkali activated slag system, the function of limestone is not well understood. LP is often regarded as an inert filler in the slag based alkali activated system [13-15]. Besides, intensive $\mathrm{Ca}^{2+}$ ions will be released from slag particles and thus the dissolution of LP releasing $\mathrm{Ca}^{2+}$ ions is actually detained compared to its hydrolysis in the low-calcium containing alkali activated system. As a result, LP is more likely to be restricted to an inert filler, acting as nucleation sites. Gao et al. [18] characterized waterglass activated slagfly ash-limestone blends, and reported that the incorporation of LP shows good filler effect by giving a slightly higher strength than that of fly ash. However, no trace of chemical involvement can be identified as there are no monocarboaluminate or new phases found on the XRD pattern. Most recently, Rakhimova et al. [22] studied the influence of different LP on the properties of slag activated by sodium carbonate based waste and found that the 28 days strength was not weakened up to $50 \%$ addition of LP (Blain fineness $\geq 400 \mathrm{~m}^{2} / \mathrm{kg}$ ). However, they stated that the benefits on the strength development is mainly attributed to the "physical activity" of LP.

Compared to waterglass, sodium carbonate as an activator shows enhanced contribution concerning setting time and shrinkage [2, 23, 24]. Besides, the production of $\mathrm{Na}_{2} \mathrm{CO}_{3}$ is more cost-effective and environmentally friendly compared to other activators [25]. It is noteworthy that LP could act differently in sodium carbonate activated slag (SCAS) system due to its particular reaction mechanism compared to slags activated by waterglass or sodium hydroxide [4, 26, 27]. As reported by Bernal et al. [4] and our previous study [26], $\mathrm{CO}_{3}{ }^{2-}$ anions concentration in the pore solution and the initially precipitated calcium carbonate significantly control the sodium carbonate activation process. According to the previous researches [4, 23, 28-30], the main reaction products of sodium carbonate activated slag are $\mathrm{C}-(\mathrm{A})-\mathrm{S}-\mathrm{H}$ gel, calcium carbonate $\left(\mathrm{CaCO}_{3}\right)$, gaylussite $\left(\mathrm{Na}_{2}\right.$ $\left.\mathrm{Ca}\left(\mathrm{CO}_{3}\right)_{2} \cdot 10 \mathrm{H}_{2} \mathrm{O}\right)$, hydrotalcite $\left(\mathrm{Mg}_{6} \mathrm{Al}_{2} \mathrm{CO}_{3}(\mathrm{OH})_{16}\right.$ $\left.4 \mathrm{H}_{2} \mathrm{O}\right)$, etc. With respect to the carbonates groups in the minerals, the presence of limestone could be potentially involved in the reaction, e.g. $\mathrm{Ca}^{2+}$ can be potentially involved in the formation of $\mathrm{C}-(\mathrm{A})-\mathrm{S}-\mathrm{H}$ gel. Furthermore, the incorporation of LP contributes to the strength improvement and lowered cost. Moseson [19] developed concretes with strength up to around $41 \mathrm{MPa}$ at 3 days and $65 \mathrm{MPa}$ at 28 days while the $\mathrm{CO}_{2}$ emission and energy consumption is reduced by $97 \%$ compared to Portland cement (PC) based materials. However, that research was mainly focused on the economic benefits and $\mathrm{CO}_{2}$ emission, while the chemical function of LP on the reaction of SCAS was not discussed.

The present research aims to study the effect of LP on the reaction kinetics, reaction products and strength development of sodium carbonate activated slag. The heat evolution of mixtures with different LP incorporation levels was measured, up to 7 days. Furthermore, the specimens was ground for microstructural analyses, including X-ray diffraction (XRD), Thermogravimetry and Derivative Thermogravimetry (TG-DTG) and Fourier transform infrared spectroscopy (FTIR), etc. The strength developments were characterized at different curing ages. The fresh behaviour was evaluated. The chemical involvement of LP especially at a high content in the sodium carbonate activation is observed and the related mechanism is discussed.

\section{Materials and experiments}

\subsection{Materials}

Ground granulated blast furnace slags (GGBS) (provided by ENCI B.V, the Netherlands) and limestone powder were applied as raw materials. The oxide compositions of these two materials were determined by using X-ray Fluorescence (XRF), as shown in Table 1 . The basicity coefficient of GGBS was calculated based on the chemical composition, following the formula $\left(\mathrm{K}_{\mathrm{b}}=(\mathrm{CaO}+\mathrm{MgO}) /\left(\mathrm{SiO}_{2}+-\right.\right.$ $\left.\mathrm{Al}_{2} \mathrm{O}_{3}\right)$ ), yielding 1.3. The particle size distributions (PSDs) of the GGBS and LP, determined by Mastersizer 2000, are presented in Fig. 1, with the d(0.5) of 
Table 1 Chemical composition of the GGBS determined by XRF

\begin{tabular}{lll}
\hline Chemical composition (\%) & GGBS & Limestone \\
\hline $\mathrm{SiO}_{2}$ & 35.50 & 0.84 \\
$\mathrm{CaO}$ & 38.60 & 53.96 \\
$\mathrm{Al}_{2} \mathrm{O}_{3}$ & 13.60 & 0.24 \\
$\mathrm{MgO}$ & 10.20 & 1.01 \\
$\mathrm{Fe}_{2} \mathrm{O}_{3}$ & 0.48 & 0.32 \\
$\mathrm{SO}_{3}$ & 1.27 & - \\
$\mathrm{K}_{2} \mathrm{O}$ & 0.48 & 0.34 \\
$\mathrm{TiO}_{2}$ & 1.01 & - \\
$\mathrm{Cl}$ & 0.01 & - \\
L.O.I & - & 43.01 \\
Density $\left(\mathrm{kg} / \mathrm{m}^{3}\right)$ & 2930 & 2710 \\
Blaine fineness $\left(\mathrm{m}^{2} / \mathrm{kg}\right)$ & 373 & 546 \\
\hline
\end{tabular}

$19.37 \mu \mathrm{m}$ and $10.30 \mu \mathrm{m}$, respectively. Sodium carbonate (powder form, analytical grade) was firstly dissolved in water followed by cooling down to room temperature $\left(20 \pm 1{ }^{\circ} \mathrm{C}\right)$, prior to further actions.

\subsection{Experiments}

\subsubsection{Flowability and strength test}

The starting materials (Table 2) were firstly mixed and the flowability of samples was measured by a
Hägermann cone with the diameters of: top $=70 \mathrm{~mm}$, base $=100 \mathrm{~mm}$ and height $=50 \mathrm{~mm}$. Two perpendicular diameters of the resulted paste spread were measured and the flowability of the pastes is interpreted by the average diameter. Afterwards, the fresh pastes were cast into plastic moulds $\left(40 \times 40 \times 160 \mathrm{~mm}^{3}\right)$ following the preparation procedure suggested by EN 196-1. The specimens were manually vibrated and then covered with plastic foils to prevent the potential moisture loss. After hardening, the samples were demoulded and stored in a climate chamber with the relative humidity of $>95 \%$ at room temperature $\left(20 \pm 1{ }^{\circ} \mathrm{C}\right)$ till the ages of testing.

\subsubsection{Sodium carbonate activation kinetics assessment}

The heat evolution of the designed mixtures (Table 2) was characterized by an isothermal calorimetry instrument (TAM AIR Calorimeter), set at $20{ }^{\circ} \mathrm{C}$. Fresh pastes were manually prepared and transferred to an ampoule before loading to the calorimeter. It should be noted that the measurement in the initial $\sim 45$ min might not be reliable because of the instability of the instrument and the sampling time about 4-6 min after mixing was not measured.
Fig. 1 Particle size distributions of the GGBS and LP

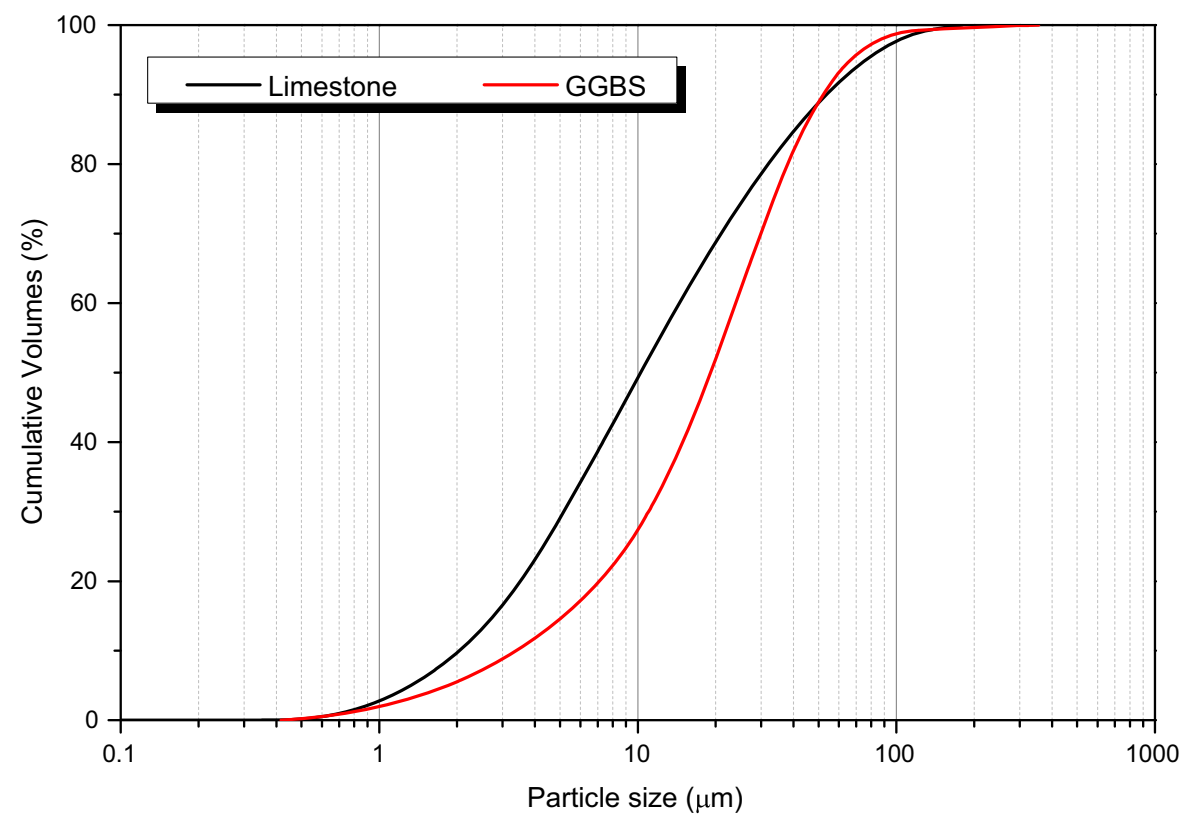


Table 2 Designed mixtures with different contents of LP

\begin{tabular}{lccll}
\hline Mixture & Slag content (wt\%) & LP (wt\%) & $\begin{array}{l}\mathrm{Na}_{2} \mathrm{CO}_{3} \text { dosage } \\
\left(\mathrm{Na}_{2} \mathrm{O} \text { wt } \%\right)\end{array}$ & Water/solid ratio (-) \\
\hline Ref. & 100 & 0 & $4.0 \%$ & 0.4 \\
LP 5\% & 95 & 5 & & \\
LP 10\% & 90 & 10 & & \\
LP 15\% & 85 & 15 & & \\
LP 30\% & 70 & 30 & & \\
\hline
\end{tabular}

\subsubsection{Microstructural analysis}

The remaining samples after strength tests were ground into powders $(\approx 63 \mu \mathrm{m})$ for the reaction products and microstructural analyses. The reaction products of the samples were analyzed by X-ray diffractometry (XRD) analysis using a $\mathrm{Cu}$ tube $(20 \mathrm{kV}, 10 \mathrm{~mA})$ with the settings of: scanning range $3^{\circ}-50^{\circ}$, step of $0.02^{\circ}$ and measuring time 3 s/step. About 40-70 mg powdered samples were measured by thermogravimetric analysis (TGA), and further evaluated with derivative thermogravimetric analysis (DTG). The specimen was firstly isothermally held at $20{ }^{\circ} \mathrm{C}$ for $3 \mathrm{~h}$ to stabilize the internal balance of instrument before heated up to $1000{ }^{\circ} \mathrm{C}$ with the rate of $1{ }^{\circ} \mathrm{C} / \mathrm{min}$, using nitrogen $(40 \mathrm{ml} / \mathrm{min})$ as the carrier gas. The FT-IR spectra scanned 12 times from 4000 to $400 \mathrm{~cm}^{-1}$ were collected by applying a PerkinElmer Frontier $^{\mathrm{TM}}$ IR/FIR Spectrometer with the attenuated total reflection (ATR) method (GladiATR, crystal diamond) at a resolution of $4 \mathrm{~cm}^{-1}$ using the ground solid powders.

\section{Results and discussion}

\subsection{Flowability}

As shown in Fig. 2, the incorporation of LP increases the flowability of the mixtures up to a replacement level of about $15 \%$. When further increasing the dosage of LP to $30 \%$, the workability of the mixtures is slightly decreased. Improvement on the fresh behavior of pastes were also observed in PC based materials after incorporating LP [31, 32]. This can be contributed by two mechanisms. Firstly, the packing of the mixture is improved by the applied LP as it is finer than slag particles (see Blaine fineness), leading to a better flowability. A similar phenomenon was found

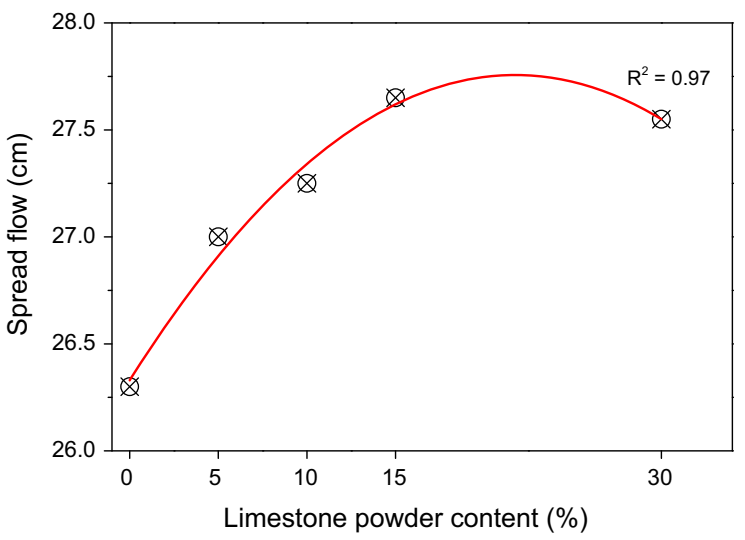

Fig. 2 Spread flow of the mixtures versus the LP content

by Brouwers and Radix [33] and Quercia et al. [34] that an improved packing of mixtures leads to a better spread flow. Secondly, due to the presence of sodium carbonate in the solution, the dissolution of LP is prohibited because of the saturation limitation. The LP consumes less water than slag particles as the dissolution of those particles increases the water demand. However, when increasing the dosage of LP from 15 to $30 \%$, the flowability of the mixture decreases, which can be explained by the reduced volume percentage of water.

It should also be noted that the fresh behavior is also affected by the initial reaction of sodium carbonate activated slag, i.e. precipitation of $\mathrm{CaCO}_{3}$ and gaylussite [35]. Due to the high concentration of $\mathrm{CO}_{3}{ }^{2-}$ anion provided by the activators and low saturation limit of $\mathrm{CaCO}_{3}$, the precipitation and formation of gaylussite will quickly occur when slag starts to release $\mathrm{Ca}^{2+}$ ions. The early age reaction will negatively affect the flowability of the samples. By replacing slag particles, the initial reaction is delayed to a certain content (when the LP dosage $\geq 10 \%$ ), as shown in the calorimetric results (Fig. 4). Consequently, the workability of the pastes is improved. 


\subsection{Sodium carbonate activation kinetics}

Figure 3 presents the heat evolution of sodium carbonate activated slag with different LP replacement levels. It is shown that the reaction process of SCAS incorporating LP is similar to that of PC hydration or other alkali activated materials [36-39], which can generally be divided into five stages. Similar to the previous research results $[4,26]$, the dormant periods of the mixtures are relatively long due to the initial precipitation of calcium carbonate. As depicted in Fig. 3, with 5\% LP addition, the heat release intensities of the samples are slightly improved, indicating a slightly faster reaction of slag particles after incorporating LP. When increasing the LP dosage to $10 \%$, the reaction is delayed but the intensity is increased. However, further increasing the LP content leads to a slower and less intensive reaction as shown in Table 3 . It should be noted that LP with $10 \%$ replacement level gives the strongest intensity on the heat evolution, indicating the optimal effects of LP addition (replacement levels between 5 and 30\%). The same trend is also found in the compressive strength development of the samples containing different levels of LP (Fig. 4).

$\mathrm{Ke}$ et al. [30] investigated the reaction kinetics of SCAS by using calcined layered double hydroxides
(CLDH), which removed the $\mathrm{CO}_{3}{ }^{2-}$ anions, yielding a significant rise in the $\mathrm{pH}$ and consequently fast reaction. Bernal et al. [4] also reported that the concentration of $\mathrm{CO}_{3}{ }^{2-}$ anions in the pore solution plays a significant role on the early age reaction of SCAS. In the current study, the incorporated LP provides extra surface areas for the precipitation of reaction products, but, in the meantime sufficient $\mathrm{Ca}^{2+}$ ions need to be dissolved to consume the same amount of $\mathrm{CO}_{3}{ }^{2-}$ anions which require a further dissolution of slag particles due to the dilution effect, i.e. a deeper dissolution. In this case, the incorporation of LP can accelerate (mixture LP 5\%) or intensify (mixture LP $10 \%)$ the reaction. However, dilution of binder can also lead to the reduction on the intensity and the time to reach the reaction peak, especially when the replacement level is high $(\geq 15 \%)$, as shown in Fig. 3. In PC based system, the incorporation of LP has been reported to show acceleration effect on the cement hydration [13], and both intensity and time to reach reaction peak (TTRP) were improved when PC/ $\mathrm{C}_{3} \mathrm{~S}$ were blended with LP. The similar results were obtained by Zajac et al. [40] who studied the influence of limestone on the hydration of $\mathrm{PC}$, and found that a mixture with $4 \%$ of LP addition showed a slightly faster and intensive reaction than pure PC mixture. As

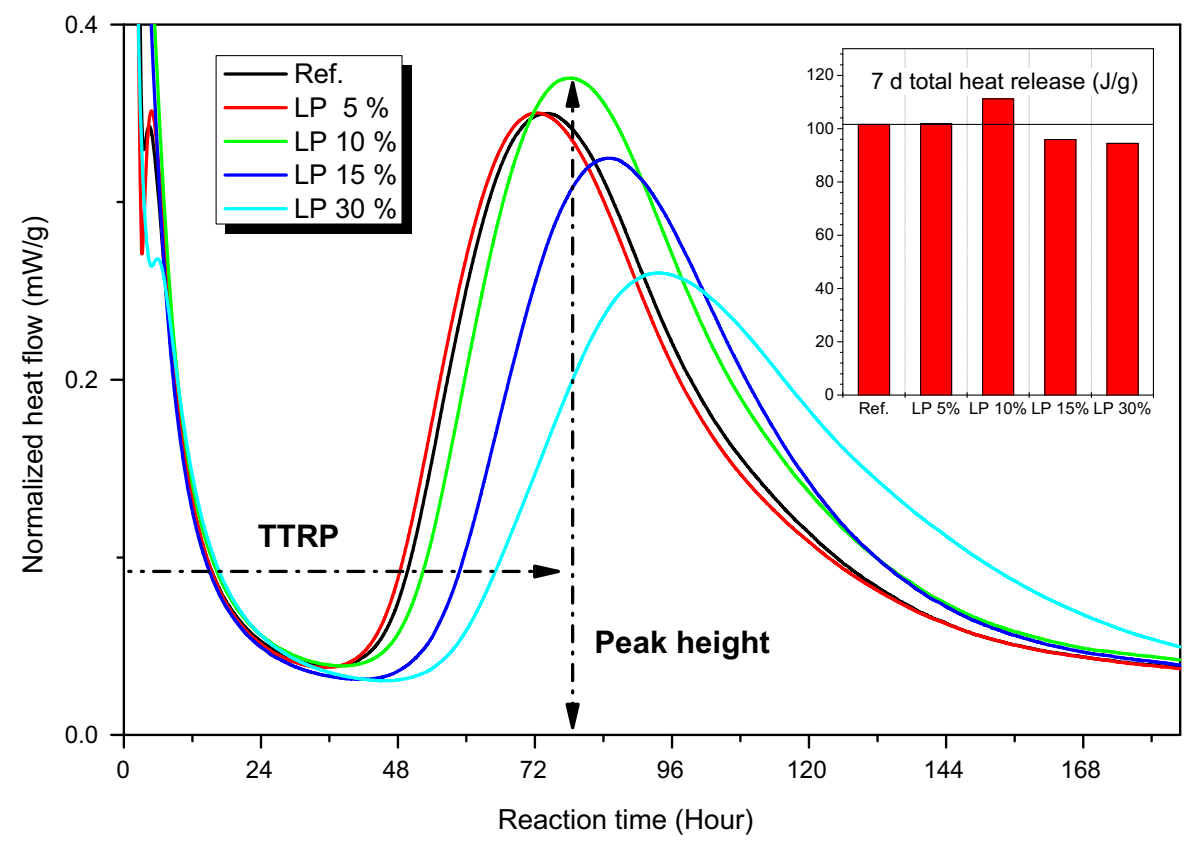

Fig. 3 Heat flow normalized by mass of GGBS and total mass 
Table 3 Summary of heat evolutions

\begin{tabular}{lllc}
\hline Mixture & Peak height $(\mathrm{mW} / \mathrm{g})$ & TTRP $(\mathrm{h})$ & Total 7 days $(\mathrm{J} / \mathrm{g})$ \\
\hline Ref. & 0.35 & 74.77 & 98.65 \\
LP 5\% & 0.35 & 72.71 & 98.95 \\
LP 10\% & 0.37 & 79.59 & 107.82 \\
LP 15\% & 0.36 & 84.65 & 93.08 \\
LP 30\% & 0.27 & 93.52 & 90.39 \\
\hline
\end{tabular}

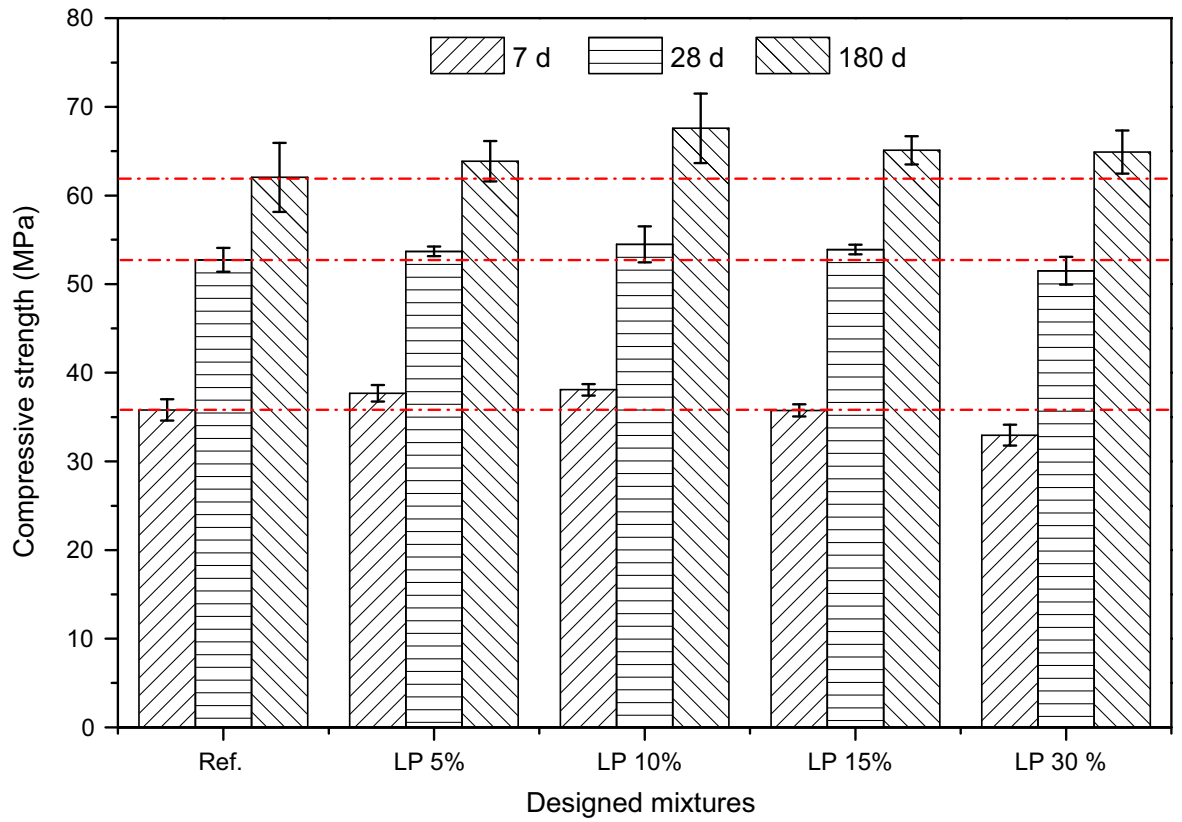

Fig. 4 Compressive strength of the mixtures at different curing ages versus the LP content

shown in Fig. 3, the acceleration effect of adding LP on the reaction was found in the sodium carbonate activated slag-LP blends when the LP content is $5 \%$. When increasing the LP content to $10 \%$ or higher, different behaviours were observed between PC and sodium carbonate activated system. This will potentially affect the reaction products as well as other hardened behaviour such as strength, and this will be discussed in the following sections.

\subsection{Compressive strength}

The compressive strength of the mixtures at different curing ages was measured and the results are shown in Fig. 4. The strength in overall ranges between 32.9 and $38.1,51.5$ and 54.5 and 62.0 and $67.6 \mathrm{MPa}$ at the curing ages of 7, 28 and 180 days, respectively. At the early stage, the mechanical properties of the mixtures increase with the increase of LP content up to $10 \%$ and then slightly decline. From the long-term strength development point of view, samples containing LP up to $30 \%$ are slightly improved compared to mixtures without LP. It is remarkable that the incorporation of LP does not weaken the mechanical strength of the samples, e.g. the compressive strength of mixture containing $30 \%$ of LP is only $2.4 \%$ lower than the reference sample (28 days).

LP has been widely applied in Portland cement based materials and its effect on the mechanical properties of PC has been intensively studied [12-15]. Kumar et al. [12] studied the replacement levels (up to $50 \%$ ) of LP on the strength development PC type I/II and found that the compressive strength of samples at different ages is roughly linearly proportional to the PC content. For example, when the PC was replaced by $30 \% \mathrm{LP}$, the compressive strength of the mixture at 
28 days is decreased from about $44 \mathrm{MPa}$ (reference without LP) to about $30 \mathrm{MPa}$, namely a relative decrease of about $32 \%$. Kumar et al. [41] investigated the influence of the LP fineness on the PC hydration and reported that after 28 days of curing all samples containing LP (15\% replacement) show similar compressive strength and the strength is about $13 \%$ lower than the reference samples. Ramezanianpour [10] reported the mechanical properties of PC based samples decrease with the increase of LP replacement levels. Nevertheless, samples with up to $10 \%$ LP replacement show comparable properties to $\mathrm{PC}$ concrete.

For the alkali activated slags (AAS), since the slags do not contain the ingredients $\mathrm{C}_{3} \mathrm{~A}$ or $\mathrm{C}_{3} \mathrm{~S}$, as a result, theoretically the benefits of incorporating limestone in the AAS are mainly based on the inert filler effect, i.e. providing extra specific surface area acting as nuclei sites. Abdalqader et al. [42] characterized the mixtures of sodium carbonate activated slag-fly ash blenders, and found that the effect of fly ash on the strength development at the early ages is not prominent. Gao et al. [18] studied the properties of alkali activated slag-fly ash blends with limestone addition using waterglass as activators, and found that increasing the LP content with a constant slag content leads to a slightly better strength development. However, in both studies, the main reaction products remain the same and no trace of chemical involvement was observed.

As for sodium carbonate activated slag, due to the initial precipitation of calcium carbonate at the very early stage [2, 4, 26], the incorporated limestone powder (calcium carbonate) can potentially influence the reaction process as they share the same chemical composition, affecting the strength development. It is certain that LP can provide extra surface area and act as nuclei sites, accelerating the reaction of the specimens. However, the dilution effect normally plays a more important role leading to a slower strength development for instance in Portland cement based system. The possible reasons for the strength enhancement of sodium carbonate activated slag blended with LP (optimal LP replacement 10\%) will be discussed in the following sections.

\subsection{XRD}

Figure 5 shows the XRD patterns of the mixtures at different curing ages. Three main phases, calcite (PDF
\#47-1743), gaylussite (PDF \#74-1235) and hydrotalcite (PDF \# 14-0191), can be identified for all the samples at the curing age of 7 and 28 days, respectively. The reflections of the calcite in the mixtures containing LP are intensive while the intensities of other crystalline phases are relatively weak. The intensities of the calcite increase with the increasing addition of LP in the mixtures, and no other polymorphous of calcium carbonate, i.e. aragonite and vaterite, are detected, possibly due to their low contents or poor crystallization.

Gaylussite is identified as a secondary reaction product for all samples prepared with different contents of LP at the early ages. No clear difference can be observed on the intensity of the produced gaylussite. When approaching the curing age of 28 days, the intensities of gaylussite for all the mixtures decrease, especially for the samples with high levels of LP replacement (over 15\%). After 180 days of curing, the reflections of gaylussite are vanished, indicating it has dissolved and converted to other reaction products [4, 43]:

$\mathrm{NaCa}\left(\mathrm{CO}_{3}\right)_{2} \cdot 5 \mathrm{H}_{2} \mathrm{O}=\mathrm{CaCO}_{3}+2 \mathrm{Na}^{+}+\mathrm{CO}_{3}^{2-}+5 \mathrm{H}_{2} \mathrm{O}$

Bernal et al. [4] reported that the entire gaylussite seems to convert to more stable products after 180 days of curing. Kovtun et al. [29] found that the intensity of gaylussite decreased in all accelerated pastes using accelerators such as sodium hydroxide and cement. The formation of hydrotalcite is also observed at the early ages but with only weak reflections (Fig. 5a), and with the ongoing reaction the intensity is increasing. Furthermore, the intensity of the hydrotalcite is improved after 28 days of curing, indicating the continuing alkali activation.

It should be noted that after 28 days of curing, the formation of natron is clearly identified in the mixtures contenting over $15 \% \mathrm{LP}$, while at the curing age of 7 days only very weak reflections at around $30.8^{\circ}$ are shown, indicating that the incorporation of LP chemically affects the reaction process. The potential mechanisms will be discussed in Sect. 4 .

\subsection{TG-DTG}

Figure 6 presents the TG-DTG results of mixtures at the curing ages of 7, 28 and 180 days, and all samples 
Fig. 5 XRD patterns of the mixtures at different curing ages as versus the LP content (strongest calcite peak is truncated for clarity)
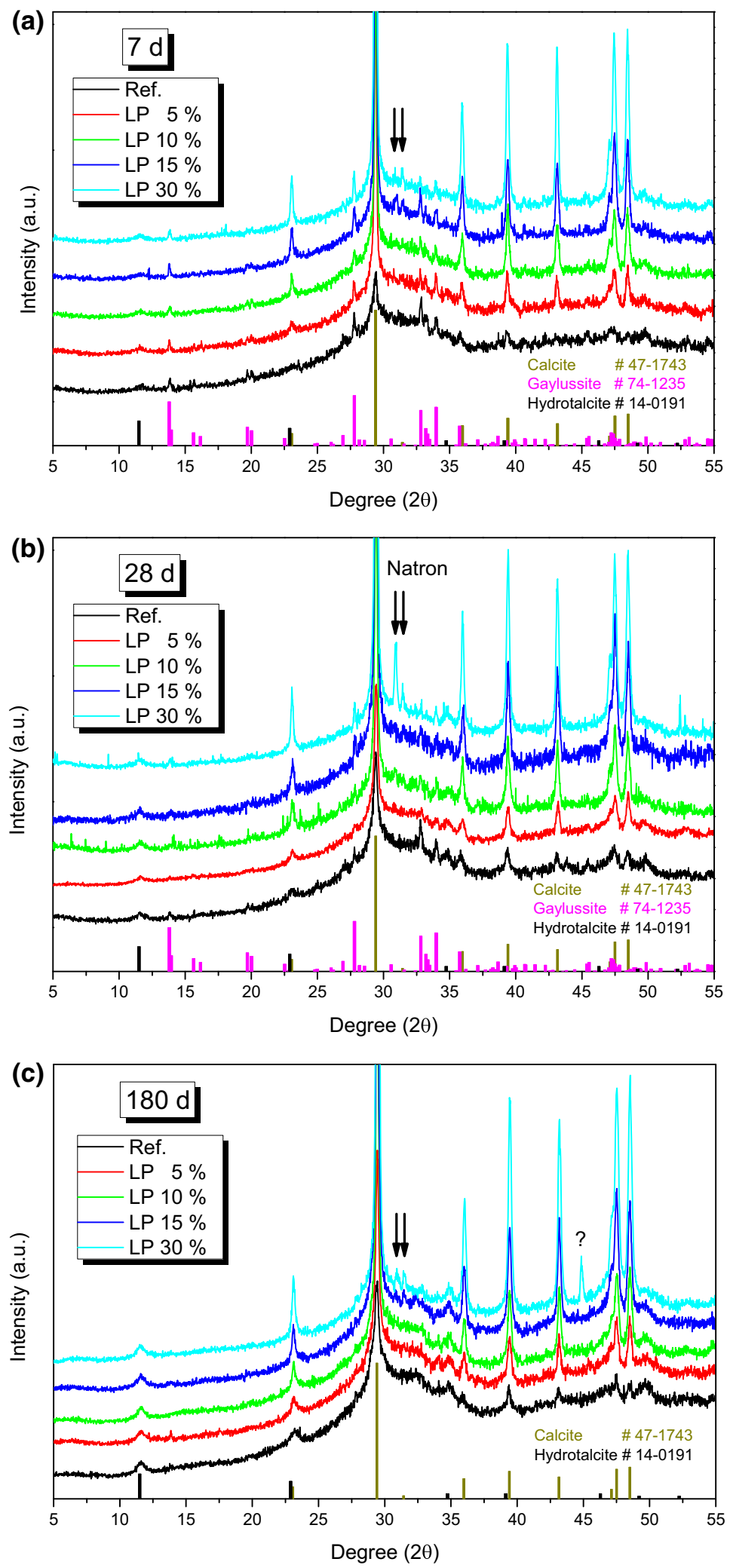
Fig. 6 TG-DTG results of the mixtures versus the LP content at the curing ages of a 7 days, b 28 days and c 180 days, respectively (the mass losses of mixture LP $30 \%$ for $\Delta m_{2}\left(400-560{ }^{\circ} \mathrm{C}\right)$ and $\Delta m 3\left(560-700{ }^{\circ} \mathrm{C}\right)$ are calculated slightly differently depending on the DTG results)
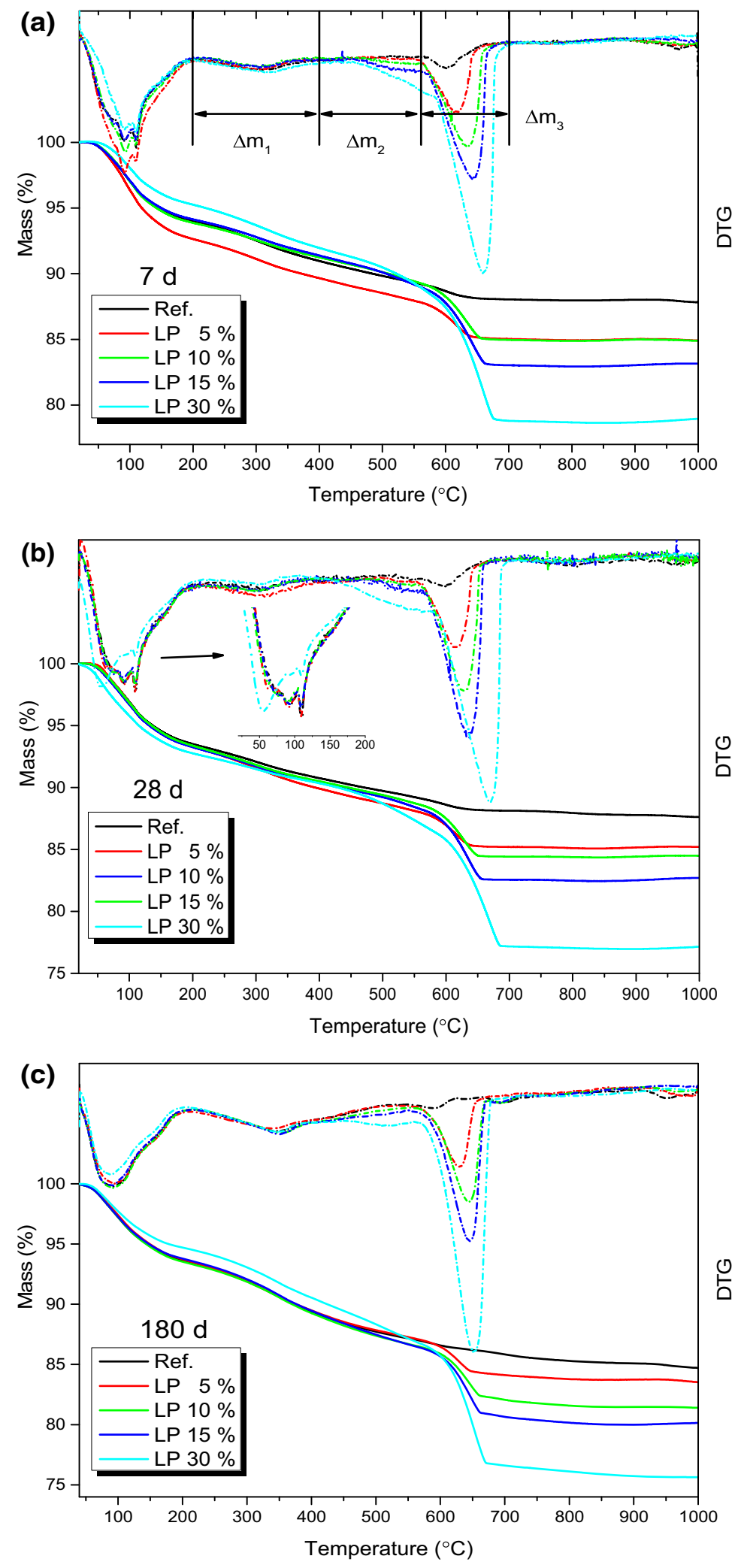
Table 4 Summary of mass loss (by percentage) at different temperature ranges (according to the definition in Fig. 6)

\begin{tabular}{|c|c|c|c|c|c|c|c|c|c|}
\hline \multirow[t]{2}{*}{ Mixture (\%) } & \multicolumn{3}{|c|}{7 days } & \multicolumn{3}{|c|}{28 days } & \multicolumn{3}{|c|}{180 days } \\
\hline & $\Delta m_{1}$ & $\Delta m_{2}$ & $\Delta m_{3}$ & $\Delta m_{1}$ & $\Delta m_{2}$ & $\Delta m_{3}$ & $\Delta m_{1}$ & $\Delta m_{2}$ & $\Delta m_{3}$ \\
\hline Ref. & 3.07 & 1.75 & 1.17 & 2.94 & 1.74 & 1.02 & 4.22 & 2.34 & 1.03 \\
\hline LP 5\% & 2.98 & 1.84 & 2.79 & 3.29 & 1.87 & 2.68 & 4.33 & 2.33 & 2.92 \\
\hline LP $10 \%$ & 2.72 & 1.97 & 4.31 & 2.87 & 1.91 & 4.15 & 4.27 & 2.68 & 4.30 \\
\hline LP $15 \%$ & 2.66 & 2.60 & 5.74 & 2.87 & 2.14 & 5.11 & 4.24 & 2.94 & 5.66 \\
\hline LP $30 \%$ & 3.29 & 3.67 & 9.49 & 2.33 & 3.89 & 8.84 & 4.16 & 3.62 & 10.16 \\
\hline
\end{tabular}

possess similar patterns by showing 3 main peaks. The first mass loss before $200{ }^{\circ} \mathrm{C}$ is caused mainly by the removal of free water and partly by the dehydration of C-(A)-S-H gel [23]. It should be noted that there are several other small separate peaks shown in the low temperature range of $20-200{ }^{\circ} \mathrm{C}$, while in the previous researches only one broad peak centred at around $105{ }^{\circ} \mathrm{C}$ is shown $[23,42]$. Considering the XRD results, these peaks can potentially be attributed to the dehydration of sodium carbonate salts. For example, natron $\left(\mathrm{Na}_{2} \mathrm{CO}_{3} \cdot 10 \mathrm{H}_{2} \mathrm{O}\right)$ is stable at room temperature but dehydrates to sodium carbonate heptahydrate, $\mathrm{Na}_{2} \mathrm{CO}_{3}$ $7 \mathrm{H}_{2} \mathrm{O}$, at $32{ }^{\circ} \mathrm{C}$ and then to sodium carbonate monohydrate, $\mathrm{Na}_{2} \mathrm{CO}_{3} \cdot \mathrm{H}_{2} \mathrm{O}$, at above $38^{\circ} \mathrm{C}$. Furthermore, most mixtures show similar trends and intensities at the low temperature range, while the mixture with $30 \%$ LP replacement shows an intensive peak at around $50{ }^{\circ} \mathrm{C}$ after 28 days of curing, indicating the dehydration of natron. The existence of natron in the reaction products is also confirmed by the XRD results as shown in Fig. 4 for the samples with a high content of LP $(\geq 15 \%)$.

The decomposition of hydrotalcite can be generally classified into three stages [44-46]: (1) removal of interlayer water before $200{ }^{\circ} \mathrm{C}$, (2) decomposition of structural hydroxyl groups $\left(\sim 350{ }^{\circ} \mathrm{C}\right)$ and finally (3) the decomposition of interlayer carbonate anions ( $\sim 440^{\circ} \mathrm{C}$ ). According to the DTG pattern, in this case, the second decomposition peak appearing at around $310{ }^{\circ} \mathrm{C}$ can be assigned to the dehydroxilation of brucite-like layers of hydrotalcite and the small shoulder at $400-560{ }^{\circ} \mathrm{C}$ could be the decarbonation of hydrotalcite. The decarbonation of the other phases happens at around $600-700{ }^{\circ} \mathrm{C}$, including: calcite, LP and gaylussite after its dehydration happening at approximate $130{ }^{\circ} \mathrm{C}$ [47]. In addition to these main peaks, the tiny peak centred at about $950{ }^{\circ} \mathrm{C}$ can be regarded as the thermal decomposition of sodium carbonate [48].

Table 4 summarizes the mass loss of mixtures at different temperature ranges, representing different reaction products as discussed above. As can be seen, at the early age (7 days), $\Delta m_{1}$ shows that higher contents of hydrotalcite-like phases are generated in the mixtures with lesser $\mathrm{LP}$ addition as more $\mathrm{Mg} / \mathrm{Al}$ are available from the slag particles. However, at advanced curing ages ( $\geq 28$ days), mixture with $5 \%$ LP gives the highest content of hydrotalcite-like phases while the differences among the mixtures are small. It is noteworthy that the mixture with LP $30 \%$ only contains $70 \%$ slag of the reference mixture. Therefore, the amount of hydrotalcite-like phases should be approximately $70 \%$ of the reference assuming a similar reaction degree, while the determined value is $99 \%$, indicating a much higher reaction degree of slag particles in this condition. Besides, a clearly increased mass loss between $400-560{ }^{\circ} \mathrm{C}$ $\left(\Delta m_{2}\right)$ and $560-700{ }^{\circ} \mathrm{C}\left(\Delta m_{3}\right)$ is observed for the decomposition of calcium carbonate minerals when increasing the LP content in the mixtures. It should be noted that a reduction on the calcite content from 7 to 28 days is observed and it then increases from 28 to 180 days in all mixtures.

\subsection{FT-IR}

Figure 7 presents the FT-IR spectra of samples with different LP contents at the curing age of 7 days. All mixtures are showing similar patterns by giving similar curves and peak positions while the intensities of the peaks vary, indicating that they all contain similar reaction products but with different contents. In general, corresponding with the peak at approximate $1640 \mathrm{~cm}^{-1}$, the broad peak centred at around $3333 \mathrm{~cm}^{-1}$ due to the scissor bending of molecular water can be considered as the $\mathrm{H}-\mathrm{O}-\mathrm{H}$ stretching vibrations, i.e. the existence of free water in the reaction products $[49,50]$. The peaks centred at about 1410, 873 and $711 \mathrm{~cm}^{-1}$ are assigned to be the vibrations of $v_{3}\left[\mathrm{CO}_{3}{ }^{2-}\right], v_{2}\left[\mathrm{CO}_{3}{ }^{2-}\right]$ and $v_{4}\left[\mathrm{CO}_{3}{ }^{2-}\right]$, 
Fig. 7 FT-IR spectra of the mixtures at the curing age of 7 days

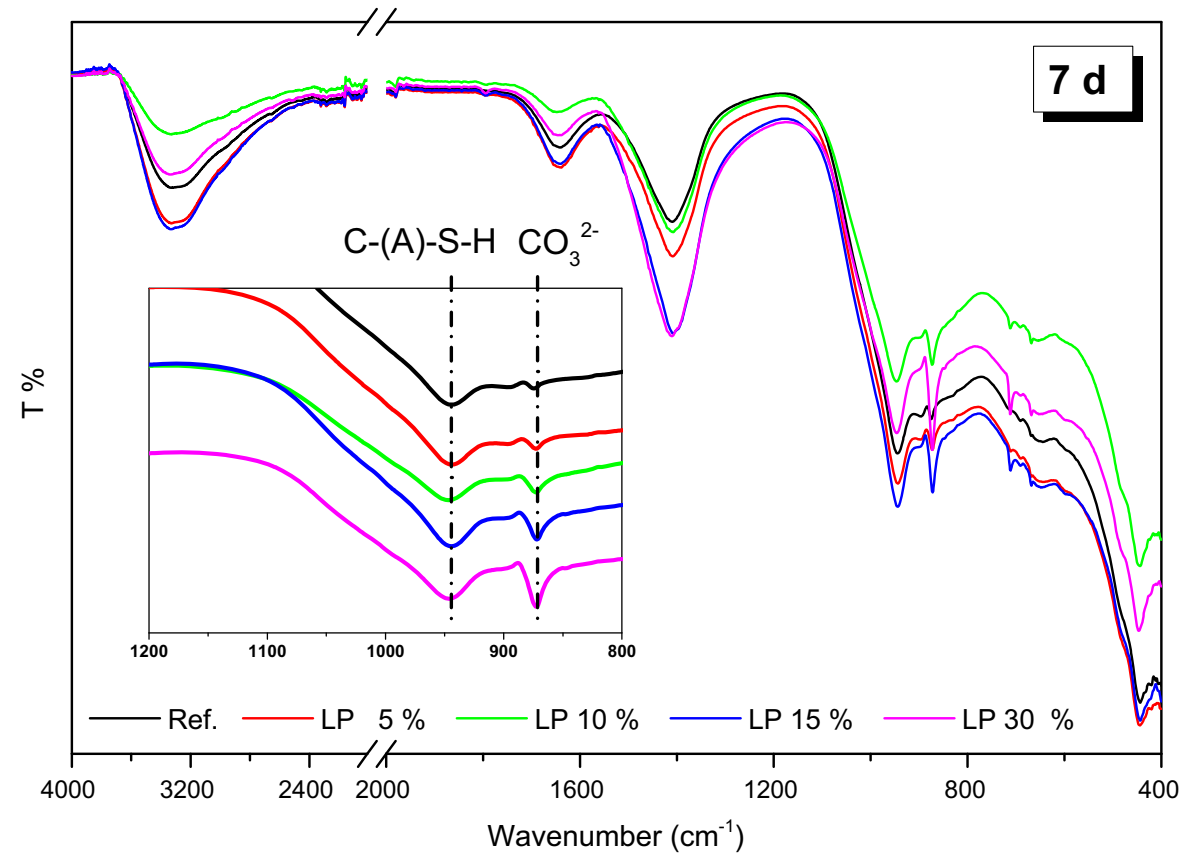

respectively, which can be attributed to the vibrations of activators used, initially precipitated calcium carbonate or generated carbonate salts such as gaylussite and hydrotalcite $[28,51,52]$. In general, the intensities of the peaks at around $873 \mathrm{~cm}^{-1}$, the vibration of carbonate anions, are proportional to the content of LP in the designed mixtures.

The sharp peak at around $946 \mathrm{~cm}^{-1}$ is generally observed for sodium carbonate activated slags of the generated $\mathrm{C}-(\mathrm{A})-\mathrm{S}-\mathrm{H}[25,42]$, while for the waterglass activated slags the position of this peak shifts to a higher wavenumber between 950 and $1000 \mathrm{~cm}^{-1}$ [52-54], pointing to a different chemical proportion (Si/Ca ratio) [51, 55, 56]. Nevertheless, the LP incorporation does not affect the peak position, indicating that the gel structure of $\mathrm{C}-(\mathrm{A})-\mathrm{S}-\mathrm{H}$ remains the same regardless of the LP dosages. However, it should be noted that the accuracy of using FTIR to check the gel structure and $\mathrm{Ca} / \mathrm{Si}$ ratio at micro-level is not fully understood yet and still open for discussion. To reach a more convincing conclusion, further research is still needed.

\section{Discussion}

The delayed reaction process is caused not only by the dilution effect, but also by the chemical effects. When having a lower slag content, the mixtures will take more time to release sufficient $\mathrm{Ca}^{2+}$ to be precipitated with $\mathrm{CO}_{3}{ }^{2-}$ anions forming $\mathrm{CaCO}_{3}$, lowering the $\mathrm{CO}_{3}{ }^{2-}$ concentration as the reaction is controlled by the concentration of $\mathrm{CO}_{3}{ }^{2-}$ anions in the pore solution [4]. Gaylussite $\left(\mathrm{Na}_{2} \mathrm{Ca}\left(\mathrm{CO}_{3}\right)_{2} \cdot 5 \mathrm{H}_{2} \mathrm{O}\right)$ is a secondary reaction product of sodium carbonate activation and will be entirely transferred to more stable products (Eq. 1) $[4,28]$. As shown in Table 4, the amounts of calcite of all samples after a long period of curing are remaining at the same levels, indicating that the released $\mathrm{CO}_{3}{ }^{2-}$ anions from gaylussite are transferred to other phases such as hydrotalcite-like phases. However, different from Rakhimova et al. [22], the formation of a new phase, natron $\left(\mathrm{Na}_{2} \mathrm{CO}_{3} \cdot 10 \mathrm{H}_{2} \mathrm{O}\right)$, is clearly observed for the samples containing $\geq 15 \%$ LP. In this case, it is most likely that insufficient ions are released from slag particles to react with $\mathrm{CO}_{3}{ }^{2-}$ anions when the dosage of LP is high, leading to the formation of natron. On the other hand, it is also reasonable to assume that the ions released by slag particles are largely consumed due to the presence of LP, indicating a higher reaction degree.

LP in general shows a negative effect on the strength development of PC based materials [9]. However, an improved strength development with up to $30 \%$ of LP addition is clearly observed for sodium carbonate-slag activation (Fig. 4). The results are in agreement with Rakhimova et al. [22], however, 
they stated that this is mainly due to the "physical activity" of LP. It is clear that the incorporation of LP densifies the microstructure and provides extra surface area for the precipitation of reaction products, which benefits the strength development.

However, it should be noted that the molar volume of natron together with re-precipitated calcite is higher than that of gaylussite which can consequently refine the pore structure (especially for mixtures containing $\geq 15 \%$ LP). Besides, the transformation of natron to calcite during the long period curing (28-180 days) also releases free water to the hydration of slag particles and the gradual precipitated calcite is similar to the carbonation process [57] which can also further modify/ alter the pore structure. On the other hand, another potential benefit of incorporating LP is that at advanced curing time the concentrations of both $\mathrm{Ca}^{2+}$ and $\mathrm{CO}_{3}{ }^{2-}$ are low, then the hydrolysis of $\mathrm{CaCO}_{3}$ can provide $\mathrm{Ca}^{2+}$ :

$\mathrm{CaCO}_{3} \rightleftharpoons \mathrm{Ca}^{2+}+\mathrm{CO}_{3}^{2-}$

which will generate $\mathrm{C}-(\mathrm{A})-\mathrm{S}-\mathrm{H}$ gel while the $\mathrm{CO}_{3}{ }^{2-}$ is consumed by the formation of carbonate-containing phases such as hydrotalcite. All of these contribute to the strength development.

In general, the chemical effects lead to an enhanced strength development, including the formation of natron originated from gaylussite and transition of natron to calcite. It is reasonable to assume that the formation of natron is mainly caused by the lack of sufficient ions from slag particles such as $\mathrm{Mg}^{2+}$ and $\mathrm{Al}^{3+}$ to react with the released $\mathrm{CO}_{3}{ }^{2-}$ anions from the conversion of gaylussite. Abdalqader et al. [28] characterized the reaction products of sodium carbonate activated slag-fly ash blenders and reported that no new phase was formed with up to $25 \%$ addition of fly ash or difficult to be identified. While, in the present study, the presence of LP in the mixture is observed to be involved in the chemical reaction.

\section{Conclusions}

The effects of limestone powder on the workability, reaction kinetics, reaction products and strength development of sodium carbonate activated slag are investigated. Different analytical approaches are applied to study the microstructure and chemical phases. Based on the obtained results, the following conclusions can be drawn:
1. The flowability of the pastes increases with the increase of LP content till the mass replacement level of $15 \%$.

2. The reaction is accelerated when the LP dosage is lower than $5 \%$ and then is delayed due to the dilution effect.

3. Considering the reaction kinetics and strength development, an optimal dosage $10 \%$ of LP replacement is concluded.

4. The presence of LP does not affect the main reaction products but chemically affects the decrystallization of gaylussite, resulting in the formation of a new phase especially when the dosage of LP is higher than $15 \%$.

5. A relatively high content of hydrotalcite-like phases is generated for the mixtures containing LP.

6. The formation and transformation process of natron result in the enhanced mechanicals properties.

Acknowledgements This research was carried out under the support of China Scholarship Council and Eindhoven University of Technology. Furthermore, the authors wish to express their gratitude to the following sponsors of the Building Materials research group at TU Eindhoven: Rijkswaterstaat Grote Projecten en Onderhoud, Graniet-Import Benelux, Kijlstra Betonmortel, Struyk Verwo, Attero, Enci, Rijkswaterstaat Zee en Delta-District Noord, Van Gansewinkel Minerals, BTE, V.d. Bosch Beton, Selor, GMB, Icopal, BN International, Eltomation, Knauf Gips, Hess AAC Systems, Kronos, Joma, CRH Europe Sustainable Concrete Centre, Cement\&Beton Centrum, Heros, Inashco, Keim, Sirius International, Boskalis, NNERGY, Millvision and Sappi.

Funding This research was carried out under the fund of China Scholarship Council and Eindhoven University of Technology. Author B. Yuan has received funding from China Scholarship Council, Ministry of Education of the People's Republic of China and Eindhoven University of Technology.

\section{Compliance with ethical standards}

Conflict of interest The authors declare that they have no conflict of interest.

Open Access This article is distributed under the terms of the Creative Commons Attribution 4.0 International License (http:// creativecommons.org/licenses/by/4.0/), which permits unrestricted use, distribution, and reproduction in any medium, provided you give appropriate credit to the original author(s) and the source, provide a link to the Creative Commons license, and indicate if changes were made. 


\section{References}

1. Pacheco-Torgal F, Castro-Gomes J, Jalali S (2008) Alkaliactivated binders: a review. Constr Build Mater 22:1305-1314. doi:10.1016/j.conbuildmat.2007.10.015

2. Jimenez AF, Puertas F (2001) Setting of alkali-activated slag cement. Influence of activator nature. Adv Cem Res 13:115-121. doi:10.1680/adcr.2001.13.3.115

3. Jimenez AF, Puertas F (2003) Effect of activator mix on the hydration and strength behaviour of alkali-activated slag cements. Adv Cem Res 15:129-136. doi:10.1680/adcr. 2003.15.3.129

4. Bernal SA, Provis JL, Myers RJ et al (2014) Role of carbonates in the chemical evolution of sodium carbonate-activated slag binders. Mater Struct 48:517-529. doi:10.1617/ s11527-014-0412-6

5. van Deventer JSJ, Provis JL, Duxson P, Lukey GC (2007) Reaction mechanisms in the geopolymeric conversion of inorganic waste to useful products. J Hazard Mater 139:506-513. doi:10.1016/j.jhazmat.2006.02.044

6. Bernal SA, Provis JL, Walkley B et al (2013) Gel nanostructure in alkali-activated binders based on slag and fly ash, and effects of accelerated carbonation. Cem Concr Res 53:127-144. doi:10.1016/j.cemconres.2013.06.007

7. Bernal SA, San Nicolas R, Provis JL et al (2013) Natural carbonation of aged alkali-activated slag concretes. Mater Struct 47:693-707. doi:10.1617/s11527-013-0089-2

8. Tennis PD, Thomas MDA, Weiss WJ (2011) State-of-the-art report on use of limestone in cements at levels of up to $15 \%$, 1-78. Portland Cement Association, Skokie, Illinois, USA

9. Diab AM, Abd Elmoaty AEM, Aly AA (2016) Long term study of mechanical properties, durability and environmental impact of limestone cement concrete. Alexandria Eng J. doi:10.1016/j.aej.2016.01.031

10. Ramezanianpour AA, Ghiasvand E, Nickseresht I et al (2009) Influence of various amounts of limestone powder on performance of Portland limestone cement concretes. Cem Concr Compos 31:715-720. doi:10.1016/j.cemconcomp. 2009.08.003

11. Voglis N, Kakali G, Chaniotakis E, Tsivilis S (2005) Portlandlimestone cements. Their properties and hydration compared to those of other composite cements. Cem Concr Compos 27:191-196. doi:10.1016/j.cemconcomp.2004.02.006

12. Kumar A, Oey T, Kim S et al (2013) Simple methods to estimate the influence of limestone fillers on reaction and property evolution in cementitious materials. Cem Concr Compos 42:20-29. doi:10.1016/j.cemconcomp.2013.05.002

13. Pera J, Husson S, Guilhot B (1999) Influence of finely ground limestone on cement hydration. Cem Concr Compos 21:99-105. doi:10.1016/S0958-9465(98)00020-1

14. Kakali G, Tsivilis S, Aggeli E, Bati M (2000) Hydration products of $\mathrm{C} 3 \mathrm{~A}, \mathrm{C} 3 \mathrm{~S}$ and Portland cement in the presence of CaCO3. Cem Concr Res 30:1073-1077. doi:10.1016/ S0008-8846(00)00292-1

15. Ipavec A, Gabrovsek R, Vuk T et al (2011) Carboaluminate phases formation during the hydration of calcite-containing Portland cement. J Am Ceram Soc 94:1238-1242. doi:10. 1111/j.1551-2916.2010.04201.x

16. Tsivilis S, Chaniotakisb E, Badogiannis E et al (1999) A study on the parameters affecting the properties of Portland limestone cements. Cem ELSEVIER Cem Concr Compos 21:107-116. doi:10.1016/S0958-9465(98)00031-6

17. Cwirzen A, Provis JL, Penttala V, Habermehl-Cwirzen K (2014) The effect of limestone on sodium hydroxideactivated metakaolin-based geopolymers. Constr Build Mater 66:53-62. doi:10.1016/j.conbuildmat.2014. 05.022

18. Gao X, Yu QL, Brouwers HJH (2015) Properties of alkali activated slag-fly ash blends with limestone addition. Cem Concr Compos 59:119-128. doi:10.1016/j.cemconcomp. 2015.01.007

19. Moseson AJ, Moseson DE, Barsoum MW (2012) High volume limestone alkali-activated cement developed by design of experiment. Cem Concr Compos 34:328-336. doi:10.1016/j.cemconcomp.2011.11.004

20. Rashad AM (2013) Alkali-activated metakaolin: a short guide for civil Engineer-an overview. Constr Build Mater 41:751-765. doi:10.1016/j.conbuildmat.2012.12.030

21. Provis JL, Bernal SA (2014) Geopolymers and Related Alkali-Activated Materials. Annu Rev Mater Res 44:299-327. doi:10.1146/annurev-matsci-070813-113515

22. Rakhimova NR, Rakhimov RZ, Naumkina NI et al (2016) Influence of limestone content, fineness, and composition on the properties and microstructure of alkali-activated slag cement. Cem Concr Compos 72:268-274. doi:10.1016/j. cemconcomp.2016.06.015

23. Jin F, Gu K, Al-Tabbaa A (2014) Strength and drying shrinkage of slag paste activated by sodium carbonate and reactive $\mathrm{MgO}$. Constr Build Mater 81:58-65. doi:10.1016/j. conbuildmat.2013.10.081

24. Duran Atis C, Bilim C, Celik O, Karahan O (2009) Influence of activator on the strength and drying shrinkage of alkaliactivated slag mortar. Constr Build Mater 23:548-555. doi:10.1016/j.conbuildmat.2007.10.011

25. Yuan B, Yu QL, Brouwers HJH (2015) Reaction kinetics, reaction products and compressive strength of ternary activators activated slag designed by Taguchi method. Mater Des 86:878-886. doi:10.1016/j.matdes.2015.07.077

26. Yuan B, Yu QL, Brouwers HJH (2015) Time-dependent characterization of $\mathrm{Na} 2 \mathrm{CO} 3$ activated slag. Cem Concr Compos (Under review)

27. Bernal SA, Provis JL, Rose V, Mejia De Gutierrez R (2011) Evolution of binder structure in sodium silicate-activated slag-metakaolin blends. Cem Concr Compos 33:46-54. doi:10.1016/j.cemconcomp.2010.09.004

28. Abdalqader AF, Jin F, Al-Tabbaa A (2015) Characterisation of reactive magnesia and sodium carbonate-activated fly ash/slag paste blends. Constr Build Mater 93:506-513. doi:10.1016/j.conbuildmat.2015.06.015

29. Kovtun M, Kearsley EP, Shekhovtsova J (2015) Chemical acceleration of a neutral granulated blast-furnace slag activated by sodium carbonate. Cem Concr Res 72:1-9. doi:10. 1016/j.cemconres.2015.02.014

30. Ke X, Bernal SA, Provis JL (2016) Controlling the reaction kinetics of sodium carbonate-activated slag cements using calcined layered double hydroxides. Cem Concr Res 81:24-37. doi:10.1016/j.cemconres.2015.11.012

31. Zhu W, Gibbs JC (2005) Use of different limestone and chalk powders in self-compacting concrete. Cem Concr Res 35:1457-1462. doi:10.1016/j.cemconres.2004.07.001 
32. Svermova L, Sonebi M, Bartos PJM (2003) Influence of mix proportions on rheology of cement grouts containing limestone powder. Cem Concr Compos 25:737-749. doi:10. 1016/S0958-9465(02)00115-4

33. Brouwers HJH, Radix HJ (2005) Self-compacting concrete: theoretical and experimental study. Cem Concr Res 35:2116-2136. doi:10.1016/j.cemconres.2005.06.002

34. Quercia G, Husken G, Brouwers HJH (2012) Water demand of amorphous nano silica and its impact on the workability of cement paste. Cem Concr Res 42:344-357. doi:10.1016/ j.cemconres.2011.10.008

35. Yuan B, Yu QL, Brouwers HJH (2017) Evaluation of slag characteristics on the reaction kinetics and mechanical properties of $\mathrm{Na} 2 \mathrm{CO} 3$ activated slag. Constr Build Mater 131:334-346. doi:10.1016/j.conbuildmat.2016.11.074

36. Ravikumar D, Neithalath N (2012) Reaction kinetics in sodium silicate powder and liquid activated slag binders evaluated using isothermal calorimetry. Thermochim Acta 546:32-43. doi:10.1016/j.tca.2012.07.010

37. Ben Haha M, Lothenbach B, Le Saout G, Winnefeld F (2012) Influence of slag chemistry on the hydration of alkali-activated blast-furnace slag-Part II: effect of A12O3. Cem Concr Res 42:74-83. doi:10.1016/j. cemconres.2011.08.005

38. Bernal SA, Nicolas RS, Myers RJ et al (2014) MgO content of slag controls phase evolution and structural changes induced by accelerated carbonation in alkali-activated binders. Cem Concr Res 57:33-43. doi:10.1016/j.cemconres. 2013.12.003

39. Yu QL, Brouwers HJH (2012) Development of a selfcompacting gypsum-based lightweight composite. Cem Concr Compos 34:1033-1043. doi:10.1016/j.cemconcomp. 2012.05.004

40. Zajac M, Rossberg A, Le Saout G, Lothenbach B (2014) Influence of limestone and anhydrite on the hydration of Portland cements. Cem Concr Compos 46:99-108. doi:10. 1016/j.cemconcomp.2013.11.007

41. Kumar A, Oey T, Falla GP et al (2013) A comparison of intergrinding and blending limestone on reaction and strength evolution in cementitious materials. Constr Build Mater 43:428-435. doi:10.1016/j.conbuildmat.2013.02.032

42. Abdalqader AF, Jin F, Al-Tabbaa A (2015) Development of greener alkali-activated cement: utilisation of sodium carbonate for activating slag and fly ash mixtures. J Clean Prod 113:66-75. doi:10.1016/j.jclepro.2015.12.010

43. Bischoff JL, Herbst DB, Rosenbauer RJ (1991) Gaylussite formation at Mono Lake, California. Geochim Cosmochim Acta 55:1743-1747

44. Kanezaki E (1998) Thermal behavior of the hydrotalcitelike layered structure of $\mathrm{Mg}$ and Al-layered double hydroxides with interlayer carbonate by means of in situ powder HTXRD and DTA/TG. J Chem Soc, Faraday Trans 106:279-284. doi:10.1016/S0167-2738(97)00494-3
45. Rozov K, Berner U, Taviot-Gueho C et al (2010) Synthesis and characterization of the $\mathrm{LDH}$ hydrotalcite-pyroaurite solid-solution series. Cem Concr Res 40:1248-1254. doi:10.1016/j.cemconres.2009.08.031

46. Miyata S (1980) Physico-chemical properties of synthetic hydrotalcites in relation to composition. Clays Clay Miner 28:50-56. doi:10.1346/CCMN.1980.0280107

47. Jornson DR, Ross WA (1973) Gaylussite: thermal properties by simultaneous thermal analysis. Am Mineral 58:778-784

48. Kim JW, Lee HG (2001) Thermal and carbothermic decomposition of $\mathrm{Na} 2 \mathrm{CO} 3$ and $\mathrm{Li} 2 \mathrm{CO} 3$. Metall Mater Trans B 32:17-24. doi:10.1007/s11663-001-0003-0

49. Innocenzi P (2003) Infrared spectroscopy of sol-gel derived silica-based films: a spectra-microstructure overview. J Non Cryst Solids 316:309-319. doi:10.1016/S00223093(02)01637-X

50. Yusuf MO, Megat Johari MA, Ahmad ZA, Maslehuddin M (2014) Strength and microstructure of alkali-activated binary blended binder containing palm oil fuel ash and ground blast-furnace slag. Constr Build Mater 52:504-510. doi:10. 1016/j.conbuildmat.2013.11.012

51. Puertas F, Carrasco MT (2014) Use of glass waste as an activator in the preparation of alkali-activated slag. Mechanical strength and paste characterisation. Cem Concr Res 57:95-104. doi:10.1016/j.cemconres.2013.12.005

52. Garcia Lodeiro I, Macphee DE, Palomo A, Fernandez AJ (2009) Effect of alkalis on fresh C-S-H gels. FTIR analysis. Cem Concr Res 39:147-153. doi:10.1016/j.cemconres. 2009.01.003

53. Ravikumar D, Neithalath N (2012) Effects of activator characteristics on the reaction product formation in slag binders activated using alkali silicate powder and $\mathrm{NaOH}$. Cem Concr Compos 34:809-818. doi:10.1016/j. cemconcomp.2012.03.006

54. Garcia-Lodeiro I, Jimenez AF, Blanco MT, Palomo A (2007) FTIR study of the sol-gel synthesis of cementitious gels: $\mathrm{C}-\mathrm{S}-\mathrm{H}$ and $\mathrm{N}-\mathrm{A}-\mathrm{S}-\mathrm{H}$. J Sol-Gel Sci Technol 45:63-72. doi:10.1007/s10971-007-1643-6

55. Palacios M, Puertas F (2006) Effect of carbonation on alkali-activated slag paste. J Am Ceram Soc 89:3211-3221. doi:10.1111/j.1551-2916.2006.01214.x

56. Puertas F, Jimenez AF, Blanco-Varela MT (2004) Pore solution in alkali-activated slag cement pastes. Relation to the composition and structure of calcium silicate hydrate. Cem Concr Res 34:139-148. doi:10.1016/S00088846(03)00254-0

57. Ngala VT, Page CL (1997) Effects of carbonation on pore structure and diffusional properties of hydrated cement pastes. Cem Concr Res 27:995-1007. doi:10.1016/S00088846(97)00102-6 